\title{
De onbeheersbaarheid van beleidsimplementatie en beleidsintegratie
}

\author{
Duco Bannink ${ }^{*}$
}

Het artikel van Suijs en Verbon in dit Dossier over de winsten van zorginstellingen is een uiterst relevant artikel met schokkende bevindingen waarvan het noodzakelijk is dat die gepubliceerd worden. Het artikel legt de nadruk op de analyse van de financiële positie van zorginstellingen en is terughoudend, maar volkomen helder, in het duiden van verdere implicaties. Die implicaties hebben mijns inziens sterk te maken met de vormgeving van het veld. In het gedecentraliseerde zorgveld zijn gemeenten en verzekeraars verantwoordelijk voor financieel en zorginhoudelijk toezicht. Veel van de zorg die in het artikel is besproken, ligt op het raakvlak van de Wet maatschappelijke ondersteuning 2015 (Wmo 2015; gemeenten), de Zorgverzekeringswet (Zvw; zorgverzekeraars) en de Wet langdurige zorg (Wlz; Rijk). Hebben de problemen van gebrek aan toezicht en excessieve winstvorming die worden gesignaleerd in het artikel van Suijs en Verbon te maken met het functioneren van het gedecentraliseerde stelsel?

Ik denk van wel. Namelijk dat het om kleine organisaties gaat, met een specifieke doelgroep, die functioneren op het grensvlak van verschillende financieringsstromen. Ik formuleer eerst een theorie van de beleidsimplementatie en beleidsintegratie. Daarna ga ik kort in op het functioneren van het sociale domein en laat ik zien dat niet alleen theoretisch, maar ook empirisch het voeren van sturing in het sociale domein moeilijk is. In de derde paragraaf laat ik zien dat de meer excessieve gevolgen daarvan zich voordoen in de cases die Verbon en Suijs beschrijven.

\section{Beleidsimplementatie en beleidsintegratie}

Op het niveau van de beleidsimplementatie, zo betoogden we elders (Bannink, Six \& Van Wijk, 2015), gebeuren twee dingen: enerzijds gaat het erom ervoor te zorgen dat de beleidsimplementatie voldoet aan abstracte en algemene regels; anderzijds gaat het erom ervoor te zorgen dat die regels op een adequate manier toegepast worden op concrete en specifieke casussen. Het eerste vooronderstelt controle over het handelen in de beleidsimplementatie; het andere vooronderstelt aanpassing van het handelen aan specifieke condities. Deze twee functies van de beleidsimplementatie zijn noodzakelijkerwijs incongruent. De overbrugging van abstracte en algemene regel naar concrete en specifieke casus kan niet worden gedefinieerd door de regel en niet door de casus. Dit is de kern van waarom beleidsuitvoerders altijd ook beleidsmakers zijn, zoals Lipsky (1980) het formuleerde.

* Dr. Duco Bannink is redactielid van Beleid en Maatschappij en werkzaam aan de Vrije Universiteit. 
Dit leidt tot een steeds terugkerend vereiste dat ook relevant is in het gedecentraliseerde stelsel. Sterker nog, het vereiste is een van de belangrijke aanleidingen van de decentralisaties in het sociale domein: voor beleidsimplementatie is nabijheid nodig van de beleidsmaker tot de casus, omdat casusinformatie relevant is voor de toepassing van de regel. Hier kom ik later op terug.

Want eerst is van belang om een tweede vereiste te bespreken. Dat is het vereiste van de beleidsintegratie. Bij de decentralisaties in het sociale domein werd niet alleen het zwaartepunt verschoven van boven naar beneden, maar werd ook gestreefd naar de integratie van verschillende beleidsdomeinen (Bannink, 2014). De casus (een patiënt, een woonwijk, een snelweg) is een concreet, en geheel, sociaal fenomeen. Een beleidsregel formuleert een abstract vereiste op een enkel deelterrein ten aanzien van dat sociale fenomeen. De Bekker en Van der Hijden, spreken in het derde artikel van dit Dossier in dat verband over het onderscheid tussen systeem- en leefwereld.

Op het niveau van het sociale fenomeen treden allerlei verschillende problemen op. Het sociale fenomeen is een geïntegreerd geheel. De beleidsregel daarentegen is gericht op een deelterrein, dus op een uitsnede van het geheel. De decentralisaties waren mede bedoeld om met het oog op het beter behandelen van het sociale fenomeen (het geheel) te komen tot een betere afstemming van de toepassing van de beleidsregels op de verschillende deelterreinen.

We kunnen bij de combinatie van beleidsimplementatie en beleidsintegratie spreken van een 'dubbele sturingsuitdaging' (Bannink \& Bosselaar, 2018). Voor de bestuurder is de beleidsregel bekend, maar de casus niet (een probleem van verticale afstemming); en voor de bestuurder is het enkele beleidsdomein nog enigszins te overzien, maar de afstemming tussen of integratie van die beleidsdomeinen niet (een probleem van horizontale afstemming).

Er is tegelijkertijd sprake van 'complexiteit' en van 'ambiguïteit'. Complexiteit definieer ik als onzekerheid over de feitelijke kant van een probleem. De bestuurder kent minder dan de beleidsuitvoerder de feitelijke aspecten van een casus, bijvoorbeeld: wat is er precies met de cliënt aan de hand? Ambiguiteit definieer ik als onzekerheid ten aanzien van de normatieve kant van een probleem: bestuurders, uitvoerders, en bestuurders en uitvoerders onderling kunnen van mening verschillen over de meest wenselijke aanpak: waar willen we eigenlijk naartoe met deze cliënt?

Als er sprake is van een hoog niveau van complexiteit en ambiguïteit, ontstaat wat ik noem een 'dubbele sturingsuitdaging'. Er is dan een stevige afhankelijkheid van de bestuurder ten opzichte van de beleidsuitvoerder. Die heeft consequenties voor de vormgeving van de aansturing.

Bij zekerheid over feiten en normen is een vrij hiërarchische aanpak van de aansturing mogelijk. De bestuurder heeft dan grote zekerheid over het handelen van de uitvoerder. Deze zekerheid krijgt de bestuurder ten koste van de handelingsruimte van de uitvoerder. Het inperken van de handelingsruimte van de uitvoerder is alleen dan een adequaat antwoord op het aan te pakken probleem als de bestuurder goed weet wat het probleem is (lage complexiteit) en er geen gebrek aan overeenstemming is over de aanpak (lage ambiguïteit). 

(cursief)

\begin{tabular}{llll}
\hline & \multicolumn{2}{l}{ Wie draagt risico van beleidsfalen en -succes? } \\
& Bestuurder & Uitvoerder \\
\hline Wie formu- & Bestuurder & hiërarchie & prikkelsturing op uitkomst \\
leert beleids- & - bestuurder kent feiten & - bestuurder kent feiten \\
inhoud? & - geen normatief conflict & - wel normatief conflict \\
& Uitvoerder & afstemming & aansturingsmethode? \\
& & - bestuurder kent feiten niet & - bestuurder kent feiten niet \\
& & - geen normatief conflict & - wel normatief conflict \\
\hline
\end{tabular}

Vaak is er wel onenigheid over de aanpak of wel onzekerheid over de aard van het probleem, of spelen allebei de problemen.

Als er alleen onzekerheid is over de aard van het probleem, maar geen onenigheid over de aanpak, dan kan de bestuurder aan de uitvoerder vragen om los van de eigen voorkeuren (want die zijn in overeenstemming) mee te werken aan het verder in kaart brengen van het probleem. Dit zijn de impliciete vooronderstellingen van de sturingsmethode die veel wordt gebruikt in sociale wijkteams en dergelijke: men wil allemaal een integrale aanpak, zo is de vooronderstelling, dus kunnen we samen kijken naar wat er precies met de cliënt aan de hand is. Omdat er geen onenigheid is over de aanpak, kunnen we ons samen richten op het in kaart brengen van de feiten, van de omstandigheden van de cliënt.

Als er alleen onenigheid is over de aanpak, maar geen onzekerheid over de aard van het probleem, dan kan de bestuurder de uitvoerder via prikkels stimuleren om de bedoelde normatieve voorkeuren te volgen. Dit zijn de impliciete vooronderstellingen in de benadering volgens New Public Management: de doelstelling en de causale analyse van de problematiek zijn volkomen duidelijk, dus we kunnen de uitvoerder stimuleren om precies dat te doen wat nodig is om het probleem op te lossen. Omdat er geen onzekerheid is over de feiten, kunnen we de ander stimuleren de bedoelde beleidsuitkomst te produceren.

Hiermee leggen we de vooronderstellingen bloot die liggen onder de bestuurlijke aanpak die mikt op de afstemming tussen waardevrije, niet aan de eigen belangen gebonden professionals en onder de bestuurlijke aanpak die juist vooronderstelt dat professionals wel aan de eigen belangen zijn gebonden, maar dat men die belangen via prikkels kan sturen.

Bij de decentralisatie van het sociale domein is er sprake van een situatie zoals in de cel rechtsonder van tabel 1. Er is een normatief conflict (ambiguïteit) tussen bestuurder en uitvoerder en vaak ook tussen uitvoerders (beleidsdomeinen) onderling. Zo zijn de kosten van het gedecentraliseerde beleid onderwerp van continu overleg. Uitvoerende organisaties zoeken wegen om in het veranderende sociale domein hun dienstverlening op peil te houden. Hierbij is er ook sprake van onderlinge concurrentie tussen de verschillende beleidsdomeinen. Die onderlinge concurrentie is mede mogelijk omdat de medische en sociale ondersteuning die in 
het sociale domein geboden worden elkaar vaak deels overlappen. Er is sprake van 'complementaire diensten' en van 'substitutie' (Hasenfeld, 1984).

De bestuurder heeft een achterstand in termen van de kennis over de casus en in termen van de deskundigheid over de te volgen aanpak ten opzichte van de uitvoerders. De bestuurder wordt daarom geconfronteerd met onzekerheid over de feiten (complexiteit). In zo'n situatie zijn de sturingsopties voor de bestuurder sterk beperkt. Als er onduidelijkheid is over de kosten (in uren of in geld) van een bepaalde behandeling, of over de wenselijkheid van een bepaalde aanpak, kan de bestuurder niet zo goed aan een andere deskundige vragen hoe hij de aangeboden aanpak zou moeten waarderen. Die andere deskundige is immers zelf ook weer gebonden aan zijn eigen benadering en is onderdeel van het normatieve conflict. De bestuurder kan ook niet de prikkel nog scherper stellen dan hij al deed, want daarvoor mist hij de kennis over de casus en de expertise over de aanpak. Althans, de bestuurder kan wel proberen de prikkel scherper te stellen, maar hij moet verwachten dat er onbedoelde effecten optreden omdat hij vanwege een gebrek aan inzicht in de feiten niet goed de effecten van een bepaalde prikkel kan overzien. Er zal sprake zijn van een 'performance paradox' (Van Thiel \& Leeuw, 2002), namelijk een gerichtheid op de gemeten output. Het gaat om een paradox, een schijnbare tegenstelling: de bestuurder krijgt wel degelijk wat hij vraagt, maar dat is vaak niet wat hij wil (Bannink \& Trommel, 2018). Er is een 'disconnect' (Bouckaert \& Halligan, 2008) tussen de gemeten output en de beoogde outcome.

\section{Problematische beleidsimplementatie en beleidsintegratie in het sociale domein}

In eerder onderzoek (Schagen, 2018; Schonewille \& La Grouw, 2017; Koolman, 2017) hebben we gezien dat er inderdaad zowel feitelijke als normatieve onzekerheid bestaat in het sociale domein. Er is een grote afstand tussen gemeenten, zorgverzekeraars, uitvoerende organisaties en cliëntorganisaties, en een grote afstand tussen de vanuit de Zvw gefinancierde zorg en de Wmo-gefinancierde zorg.

Schagen (2018) vond dat gemeenten en zorgverzekeraars sterk verschillen in hun perspectief op zorg en zorgorganisatie. Gemeenten hebben een lokale oriëntatie die, in overeenstemming met hun wettelijke taak, is gericht op maatschappelijke zorg. Verzekeraars hebben een landelijke oriëntatie en een gerichtheid, in overeenstemming met hun taak, op medische zorg. De maatschappelijke zorg van de gemeente is soms complementair aan de medische zorg en draagt bij aan de preventie van medische zorg. De kosten voor maatschappelijke zorg door de gemeente komen in dat geval deels ten goede aan de verzekeraar, maar vergoedingen voor deze kosten komen in het uitgevoerde onderzoek niet voor. Dat is goed te verklaren, want de verzekeraar kan niet sturen op de taakuitvoering door de gemeente en zal dus terughoudend zijn om die vergoeding te bieden, en de gemeente heeft geen middelen om een dergelijke vergoeding af te dwingen bij de verzekeraar. Schagen onderzocht zes netwerken waarin gewerkt werd aan 
domein-overschrijdende samenwerking, maar in geen van de zes netwerken komt spontaan samenwerking van de grond. De eigen perspectieven van gemeente, zorgverzekeraar, zorgaanbieders blijven sterk doorwerken. In geen van de onderzochte netwerken bleek men in staat te komen tot een geïntegreerd perspectief op de zorg (beleidsintegratie) en een duidelijke taakverdeling op de maatschappelijke werkvloer (beleidsimplementatie). In een van de onderzochte netwerken heeft een van de actoren de beschikking over dermate sterke hulpbronnen dat de andere actoren kunnen worden gedwongen mee te bewegen met die centrale actor. De horizontale afstemming (beleidsintegratie) blijkt dus lastig. Daarnaast geldt dat er afhankelijkheid is van de gemeenten ten opzichte van de zorgaanbiedersorganisaties in de onderzochte netwerken. De zorgaanbieders hebben meer kennis van de te leveren zorg, van de cliëntbehoeftes en van de zorgprocessen dan de gemeenten, zodat de gemeenten de hulp van zorgaanbieders nodig hebben om tot adequate taakuitvoering te komen. Dat betekent dat ook de verticale afstemming (beleidsimplementatie) lastig is.

Uit het onderzoek van Schonewille en La Grouw (2017) naar het functioneren van de wijkverpleegkunde komt naar voren dat de scheidslijn tussen verschillende vormen van zorg onduidelijk is. Daaruit vloeit een gebrekkige afstemming tussen beleidsdomeinen (beleidsintegratie) voort en een gebrekkige aansturing van het eigenlijke werk (beleidsimplementatie). Dit duwt de wijkverpleegkundige min of meer richting het oneigenlijk gebruik van financiële middelen. Schonewille en La Grouw laten zien dat wijkverpleegkundigen werken op het snijvlak van medische en maatschappelijke zorg. Een wijkverpleegkundige komt bijvoorbeeld bij een patiënt die intensieve medische zorg nodig heeft en ziet daar dat het bed waarin de patiënt ligt sterk vervuild is. In een optimaal geïntegreerd systeem kan het werk van de wijkverpleegkundige zich volledig richten op de vanuit de Zvw bekostigde medische zorg van deze patiënt, en kan een huishoudelijke hulp zich richten op de vanuit de Wmo bekostigde maatschappelijke zorg. Dat vereist dat de wijkverpleegkundige min of meer meteen toegang heeft tot een gemeentelijke beslisser die in staat is om aansluitend de huishoudelijke hulp toe te kennen en in te zetten die nodig is om het bed van de patiënt te verschonen. Dat lukt zelden, waardoor de wijkverpleegkundige, die de medische implicaties van het vervuilde bed natuurlijk begrijpt, zich gedwongen voelt het bed te verschonen. Als we er nu grofweg van uitgaan dat de helft van de tijd bij deze patiënt is besteed aan medische handelingen en de andere helft aan de hiermee samenhangende huishoudelijke taken, dan wordt snel duidelijk dat de mate waarin dergelijke oneigenlijke bekostiging zich kan voordoen enorm is.

Rechtstreeks onderzoek naar dit fenomeen is lastig, maar recent onderzoek van het Talma Instituut (Koolman, 2017) laat zien dat zogenaamde 'niet gecontracteerde' wijkzorgaanbieders een beduidend ruimere hoeveelheid tijd per patiënt besteden dan wel gecontracteerde aanbieders. Dat is een indicatie voor de ruimte die organisaties klaarblijkelijk in de uitvoeringspraktijk hebben om zich aan de beleidsregel te onttrekken en om ruimer dan vanuit de Zvw voorgeschreven zorg te verlenen. 
In het sociale domein is de feitelijke uitvoering van het werk op de maatschappelijke werkvloer (beleidsimplementatie) slecht te sturen en is de afbakening tussen verschillende domeinen van zorg niet duidelijk (beleidsintegratie). Het is hierdoor dat oneigenlijk gebruik van zorgmiddelen kan ontstaan.

\section{De excessieve gevolgen van beleidsimplementatie en -integratie als een dubbele uitdaging}

Ik hecht er sterk aan te zeggen dat het bij het hiervoor gegeven voorbeeld over de wijkverpleegkunde uitdrukkelijk niet gaat om oneigenlijk gebruik gericht op zelfverrijking. De wijkverpleegkundige doet het werk niet om er zelf beter van te worden, maar omdat hij of zij vindt dat het nodig is. Aspecten van maatschappelijke zorg hebben medische consequenties en daarom vindt de wijkverpleegkundige het noodzakelijk om die maatschappelijke zorg te verlenen. De wijkverpleegkundige voelt de noodzaak om op het niveau van de beleidsimplementatie te corrigeren voor de gevolgen van niet optimale beleidsintegratie.

In de analyse van winsten bij kleine zorgaanbieders door Verbon en Suijs gaat het wel om excessen. Verbon en Suijs schetsen een schokkend beeld van zelfverrijking door het management van sommige zorgorganisaties. Ze gaan vrij nadrukkelijk in op instellingen in het domein van de geestelijke gezondheidszorg. Dit is bij uitstek een domein dat valt op het snijvlak van de drie belangrijkste domeinen van de zorg in Nederland: de Zvw, de Wmo 2015 en de Wlz (voor jeugdigen met psychische problematiek is ook de Jeugdwet van belang). De gemeente is vanwege de Wmo 2015 verantwoordelijk voor psychosociale hulp, de zorgverzekeraar regelt de financiering van en toegang tot geestelijke gezondheidszorg, en in de Wlz is de zorg geregeld voor mensen die voortdurend toezicht nodig hebben of langdurig opgenomen zijn in een instelling. Hierom is beleidsintegratie erg moeilijk. Daarnaast geldt in dit domein ook enerzijds dat de medische expertise sterk gebonden is aan de zorgaanbieder en dat anderzijds de kennis over de cliënt sterk, zoals dat heet, 'contextgebonden' is, dus in de context van de behandelingsrelatie tot stand komt. Hierdoor is de beheersing van de beleidsimplementatie ook problematisch. Deze combinatie van factoren leidt tot een 'dubbele uitdaging'. De bestuurder (in dit geval de gemeente) kent de feiten niet (complexiteit) en er is een normatief conflict (ambiguïteit). De zorgaanbieder (in dit geval de kleine instellingen uit het onderzoek van Verbon en Suijs) aan de andere kant heeft een informatievoorsprong over de conditie van de cliënt ten opzichte van de bestuurder (complexiteit) en er is onduidelijkheid over de toe te passen behandeling (ambiguiteit). Hoe sterker deze informatievoorsprong en onduidelijkheid, hoe meer een uitvoerende organisatie (de zorgaanbieder) zich kan onttrekken aan de sturing door de bestuurder (de gemeente). Het lijkt erop dat dit aan de orde is in het geval van de kleinere organisaties in dit domein, met een sterk specifieke taakinvulling of doelgroep. In sommige gevallen, daar waar de zorgaanbieder sterk op het eigen belang is gericht, blijkt het mogelijk de gebrekkige sturingsmogelijkheden van de gemeente aan te wenden, met de door Verbon en Suijs gevonden excessieve gevolgen. 


\section{Literatuur}

Bannink, D. (2014). Decentralised integration of social policy domains. In: K. Farnsworth, Z. Irving \& M. Fenger (red.), Social Policy Review. Analysis and debate in social policy, 26: 221-238.

Bannink, D., \& Bosselaar, H. (red.) (2018). Het probleem samenwerken. Duiden en verbinden: ironische uitwegen voor vastgelopen samenwerking. Den Haag: Boom bestuurskunde.

Bannink, D., Six, F., \& Wijk, E. van (2015). Bureaucratic, market or professional control? A theory on the relation between street-level task characteristics and the feasibility of control mechanisms. In: P. Hupe, M. Hill \& A. Buffat (red.), Understanding Street-Level Bureaucracy. Bristol: Policy Press, 205-226.

Bannink, D., \& Trommel, W. (te verschijnen 2018). Intelligent modes of imperfect governance. Policy and Society.

Bouckaert, G., \& Halligan, J. (2008). Managing performance, international comparisons. Londen: Routledge.

Hasenfeld, Y. (1983). Human Service Organizations. Upper Sade River: Prentice Hall.

Koolman, X. (2017). Uitgavengroei niet-gecontracteerde GGZ en wijkverpleging; inventarisatie op basis van Zvw-declaraties 2014-2017. Amsterdam: Talma Instituut.

Lipsky, M. (1980). Street-level bureaucracy. Dilemmas of the individual in public services. New York: Russell Sage Foundation.

Schagen, I. (2018). Samenwerking in het gedecentraliseerde zorgdomein: alleen als het past bij de eigen positie. In: D. Bannink \& H. Bosselaar (red.), Het probleem samenwerken. Duiden en verbinden: ironische uitwegen voor vastgelopen samenwerking. Den Haag: Boom bestuurskunde, 97-109.

Schonewille, A., Grouw, Y. la (2017). Werkbare samenwerking. Mogelijkheden en moeilijkheden in de samenwerking van wijkverpleegkundigen met andere partijen. Amsterdam: Talma Instituut.

Thiel, S. van, \& Leeuw, F. (2002). The performance paradox in the public sector. Public Productivity and Management Review, 25 (3): 267-281. 